\title{
Illuminance of FL Tubes Controlled by Depths of Gap Between Positive Column and Phosphor Screen
}

\section{Lyuji Ozawa}

The Japanese Government licensed consultant in science, Beijing, China

\section{Email address:}

rotsun4@hotmail.com

\section{To cite this article:}

Lyuji Ozawa. Illuminance of FL Tubes Controlled by Depths of Gap Between Positive Column and Phosphor Screen. Science Research. Vol. 3, No. 3, 2015, pp. 93-104. doi: 10.11648/j.sr.20150303.18

\begin{abstract}
Since the opaque phosphor screens cover up the inside of the FL tubes, the presence of the depths of the gap between positive column and phosphor screen has ever reported in the study on the lighted FL tubes since the invention of the FL tube. It has found that the depths of the gap in the lighted FL tubes conceal the unrivaled advantage of the FL tubes over the solid lighting devices. The invisible depths of the gap are non-distractively and quantitatively determined by the measurements of the build-up curve of the light intensities from the lighted FL tubes in the Ulbricht Sphere. The determined depth of the gap of the selected commercial $40 \mathrm{~W}-\mathrm{HCFL}$ tube as the best one was $3 \times 10^{-3} \mathrm{~m}$. The depths of the gap are markedly changed with the FL producers, indicating no quality control of the gaps. The unexcited $\mathrm{Hg}$ atoms in the gap act as the optical filter for the UV lights from the positive column before reaching to the phosphor screen. The results suggest us that if the depth of the gap reduces to $3 \times 10^{-4} \mathrm{~m}$, the illuminance $\left(\mathrm{lm} \mathrm{m}^{-2}\right)$ of the present 40W-HCFL tube will go up to 2.5 times. The systematic study on the gaps of the lighted FL tube remains for a future study.
\end{abstract}

Keywords: Illuminance, FL Tube, Positive Column, Phosphor Screen, Depth of Gap

\section{Introduction}

FL tubes are constructed with only five parts; (a) vacuum-sealed glass tube that contains (b) a pair of metal electrodes, (c) Ar gas pressures at around $930 \mathrm{~Pa}$ (7 Torr), (d) $\mathrm{Hg}$ droplets in mg order, and (e) phosphor screen. The widely accepted FL tubes on the market have the outer diameter in 3.2 $\mathrm{x} 10^{-2} \mathrm{~m}$ (T-10) with the lengths shorter than $1.2 \mathrm{~m}$ without the reasonable explanation. With (i) the simple structure of the FL tube, (ii) simple production facilities, (iii) the studies for a long time (more than 80 years), (iv) large annual production volume on the world, and (v) many published text books and technical papers, it has believed that the technologies involved in the production of the FL tubes have well optimized as the mature technology.

The most advanced science technologies inform us that the Ar gas space in the FL tubes is not the electric conductor, like as the solids and liquids. Individuals of inert Ar atoms in the FL tubes float in vacuum with the Maxwell-Boltzmann distribution. The average separation distance of Ar atoms in FL tubes is $2 \times 10^{-7} \mathrm{~m}$ [1]. The isolation of the floating Ar atoms in FL tubes may confirm the measurement of the absorption spectrum of the Ar atoms by a spectrometer in a high resolution. The determined spectrum consists with the absorption lines, indicating that the floating Ar atoms in vacuum isolate each other.

The Ar gas space differs from the solids with the separation distance. We cannot take the concepts of the solids for the analysis of the lighting mechanisms in the lighted FL tubes. The electrons that move on in the vacuum of the Ar gas space in FL tubes do not receive the thermal perturbation from the neighboring $\mathrm{Ar}$ atoms in the vacuum. The thermal perturbation gives the electric resistance to the moving electrons. The moving electrons in the Ar gas space in the lighted FL tubes do not have the electric resistance. Consequently, the moving electrons in the Ar gas space in lighted FL tubes do not generate the Joule Heat in the Ar gas space. The heat of the Ar gas in the lighted FL tube is a prerequisite condition for the evaporation of the $\mathrm{Hg}$ atoms from the $\mathrm{Hg}$ droplets on the phosphor screen. The Ar gas space in the lighted FL tubes solely heats up with the ionization of the $\mathrm{Ar}$ atoms $\left(\mathrm{Ar}^{1+}\right)$ by the change in the entropy.

On the other hand, the solid lighting devices like as LED unavoidably have the electric resistance by the thermal 
perturbation from the thermally vibrating atoms at the lattice sites with $10^{-10} \mathrm{~m}$ separation. The solid lighting devices inevitably generate the Joule Heat in the operation. As described above, the behavior of the moving electrons in the lighted FL tubes totally differs from the behavior of the moving electrons in the solids.

There is another difference between the Ar gas space in FL tube and solids. The vacuum between Ar atoms in unlighted FL tubes fills up with the negative electric field from orbital electrons in the Ar atoms. The presence of the negative electric field in the Ar gas space in the unlighted FL tubes has ever reported in the past study on the FL tubes. The presence of the negative electric field in the vacuum between floating Ar atoms has well studied by the absorption spectrum of the analytical chemistry. The energy levels of the Ar atoms in the unlighted FL tube split many sublevels by the Stark Effect. The Stark Effect indicates the presence of the electric field from the orbital electrons of the neighboring Ar atoms $\left(F_{\text {orb }}\right)$ in the $\mathrm{Ar}$ gas space in the unlighted FL tube. The negative electric field from the $\mathrm{F}_{\text {orb }}$ in the vacuum of the unlighted FL tubes should be neutralized for the moving electrons in the vacuum of the Ar gas space. The high threshold voltage ( $>1$ $\mathrm{kV}$ ) requires for the neutralization of the negative field in the vacuum [1]. The threshold voltage corresponds to the formation of the volume of the glow lights or corona lights, hereafter the glow lights, in the Ar gas space [2, 3, 4]. On the other hand, the electrodes of the solid devices directly inject the electrons into the solids.

The volume of the formed glow lights in the Ar gas space contains large number of ionized $\mathrm{Ar}$ atoms $\left(\mathrm{Ar}^{1+}\right)$, free electrons, excited $\mathrm{Ar}$ atoms $(\mathrm{Ar} *)$, and Ar atoms. The $\mathrm{F}_{\text {orb }}$ in the vacuum of the glow lights is electrically neutralized by the presence of the ionized $\mathrm{Ar}$ atoms $\left(\mathrm{Ar}^{1+}\right)$. The $\mathrm{F}_{\text {orb }}$ is confined at the around Ar atoms. The difficulty of the start of the lighting of the FL tubes relates to the formation of the glow lights [2]. It is not the ignition of the inert $\mathrm{Ar}$ atoms that has been considered in the study on the FL tubes $[5,6,7]$.

The initial formation of $\mathrm{Ar}^{1+}$ in unlighted FL tubes is made by the formation of the volume of the glow lights in the Ar gas space [2]. The negative electric field at nearby the volume of the glow lights is also neutralized by presence of the $\mathrm{Ar}^{1+}$ in the glow lights. The free electrons in the volume of the glow lights accelerate under the $\mathrm{F}_{\text {vect. }}$ The accelerated electrons may step out from the volume of the glow lights. The stepped electrons in the Ar gas space move on to the longitudinal direction in the Ar gas space under the $F_{\text {vect }}$. The moving electrons under the $\mathrm{F}_{\text {vect }}$ meet the Ar atoms and ionize it in the rest Ar gas space. The neutralization of the vacuum by the moving electrons propagate from the volume of the glow lights to the entire area of the Ar gas space with the moving speed of the electrons that is $10^{5} \mathrm{~m} \mathrm{~s}^{-1}$ [1]. The large vacuum space of the lighted FL tubes does not fill up with the $\mathrm{F}_{\text {orb. }}$. The influence range of the $\mathrm{F}_{\text {orb }}$ confines at around $\mathrm{Ar}$ atoms. Consequently, the lighted FL tubes provide the wide superconductive vacuum for the moving electrons. The moving electron multiply meet with the Ar atom and ionizes and excites the $\mathrm{Ar}$ (and evaporated $\mathrm{Hg}$ ) atoms until the collection by the anode. The origin of the lights in the FL tubes is assigned by the excitation of the $\mathrm{Hg}$ atoms evaporated in the Ar gas space. The multiple excitations of the $\mathrm{Hg}$ atoms by the moving electron in the superconductive vacuum of the lighted FL tube give the astronomical quantum efficiency $\eta_{\mathrm{q}}=10^{13}$ visible photons per unit volume of Ar gas space and per second, $\left(\mathrm{m}^{3}, \mathrm{~s}\right)^{-1}[1]$. The astronomical quantum efficiency of the FL tubes is an unrivaled advantage of the FL tubes over other light sources. The solid lighting devices have only $\eta_{\mathrm{q}}<$ 1.0 .

The unrivaled advantage of the FL tubes had concealed by the evaluation of the lighted FL tubes by the invalided luminous efficiency $\left(1 \mathrm{~m} \mathrm{~W}^{-1}\right)$ in the study on the FL tubes [5, 6]. The luminous efficiency $\left(\mathrm{lm} \mathrm{W}^{-1}\right)$ is for the study on the colorimetry, and is not for the evaluation of the light sources. The light sources should evaluate with (a) luminance $\left(\mathrm{cd} \mathrm{m}^{-2}\right)$, or illuminance $\left(\mathrm{lm} \mathrm{m}^{-2}\right)$ and irradiance $\left(\mathrm{W} \mathrm{m} \mathrm{m}^{-2}\right)$. The performance of the FL tubes is never evaluated by the invalided luminous efficiency $\left(\mathrm{lm} \mathrm{W}^{-1}\right)$. We will concentrate here the restriction of the moving electrons in the Ar gas space of the lighted FL tubes. There are many overlooks in the study on the FL tubes for the restriction of the moving electrons in the Ar gas space. We must clarify the overlooked items before the study on the restriction of the moving electrons in lighted FL tubes.

The floating Ar atoms in the vacuum still hold the localized $\mathrm{F}_{\text {orb }}$ at around $\mathrm{Ar}$ atoms. The moving electrons in the lighted FL tube may meet the floating Ar atoms. The approaching electron to the Ar atoms cannot penetrate into the orbital shells of the Ar atom. The approaching electron to the Ar atom receives the strong Coulomb's repulsion from the localized $\mathrm{F}_{\text {orb }}$ on the Ar atoms. The repulsed electron from the Ar atom gives some amount of the kinetic energy to the Ar atom. The Ar atom ionizes or excites by the received kinetic energy from the moving electron. The repulsed electron from the Ar atom is the scattered electron from the longitudinal direction under the $F_{\text {vect }}$. The scattered electron takes again under the $F_{\text {vect }} \geq$ $F_{\text {orb }}$. The scattered electron gains the kinetic energy from the longitudinal electric field of the $\mathrm{F}_{\mathrm{vect}}$. The accelerated electron in the $F_{\text {vect }} \geq F_{\text {orb }}$ meets other Ar atom. The electrons from the cathode move on in the superconductive vacuum by the repetition of the meeting with Ar atoms, scattering from the longitudinal direction, and gaining the kinetic energy in the vacuum of the $F_{\text {vect }} \geq F_{\text {orb }}$ until the collection of the moving electrons by the anode of the internal DC electric circuit.

The operation of the lighted FL tubes is made by the moving electrons that have the negative charge of $1.6 \times 10^{-19}$ Coulomb each. The moving electrons in the vacuum are influenced with the magnetic and electric fields. Each moving electron in the vacuum may generate the magnetic field. The generated magnetic field by the moving electrons in $2 \times 10^{-4}$ A maximum [2] is negligible small level in the practical consideration. We assume no magnetic field involves in the lighted FL tube. The moving electrons in the FL tube are sensitively influenced by the electric fields in the vacuum of the lighted FL tubes.

There are three kinds of the electric fields in the lighted FL tube; (i) $F_{\text {vect, }}$ (ii) $F_{\text {orb}}$, and (iii) $F_{\text {phos }}$ of the electric field from 
the phosphor particles in the screen. The $F_{\text {vect }}$ is the longitudinal electric field of the FL tube that forms between electrodes of the internal DC electric circuit [2]. The $\mathrm{F}_{\text {orb }}$ and $\mathrm{F}_{\text {phos }}$ are localized (scalar) electric field in the lighted FL tube. The moving electrons in the lighted FL tubes are influenced with the combinations of three different scalar electric fields. The operation of the each FL tube should control the combinations of the $\mathrm{F}_{\text {vect }}, \mathrm{F}_{\text {orb }}$, and $\mathrm{F}_{\text {phos. }}$. The $\mathrm{F}_{\text {vect }}$ and $\mathrm{F}_{\text {orb }}$ are well known in the study of the FL tubes. The $F_{\text {phos }}$ is overlooked in the study of the lighted FL tubes with the consideration as the transducer from the UV lights to the visible lights.

Historically, the phosphor screen has been considered as a transducer from the UV lights to the lights in the visible spectral wavelengths. The UV photons do not have the electric charge. The operation of the FL tubes uses the excitation of the $\mathrm{Hg}$ atoms by the moving electrons. The moving electrons in the lighted FL tubes are sensitively influenced with the localized $\mathrm{F}_{\text {phos. }}$. The phosphor screens in the FL tubes act as the transducer and also act as the control of the moving electrons. This report will pay the attention to the moving electrons that are influenced by the $F_{\text {phos. }}$. The $F_{\text {phos }}$ consists of (a) the intrinsic and extrinsic electric charges in and on the phosphor particles, (b) the charges of the adsorbed residual gases, $F_{\text {gas }}$, on the surface volume in the atomic layers on the phosphor particles and in the inner glass wall [8, 9, 10], and (c) the charges of the contaminated insulators on the surface of the phosphor particles.

The common phosphor screens in the FL tube before 1975 were the $\mathrm{Ca}_{3}\left(\mathrm{PO}_{4}\right)_{4}(\mathrm{~F}, \mathrm{CL}): \mathrm{Sb}: \mathrm{Mn}$ white emitting phosphor screen. Each phosphor particle has the trapped electrons at the luminescence centers of $\mathrm{Sb}^{3+}$ and $\mathrm{Mn}^{2+}$. The trapped electrons in the phosphor screen can be studied by the measurements of the thermoluminescence as a function of the heating temperatures [8]. The intrinsic $\mathrm{F}_{\mathrm{phos}}$ is given by the trapped electrons in the luminescence centers of the phosphor particles in the screens. The approaching electrons to the phosphor screen receive the strong Coulomb's repulsion from the $F_{\text {phos }}$. The moving electrons in the Ar gas space in the lighted FL tubes never get in the phosphor screen. The repulsed electrons from the phosphor screen move on in the vacuum of the Ar gas space that the volume is defined by the $F_{\text {vect }} \geq F_{\text {phos }}$. The volume of the Ar gas space that the electrons move on in the Ar gas space is called as the positive column. With this reason, the electric conductance of the phosphor screen does not involve in the lighted FL tubes that has considered $[5,6]$. Naturally, there is the gap between positive column and phosphor screen in the Ar gas space defined by the $F_{\text {vect }} \geq F_{\text {phos }}$. The depths of the gap in the lighted FL tubes have ever reported with the invisibility by the naked eyes.

The depths of the gap work as the negative factors for the performance of the lighted FL tubes. This report will quantitatively describe the details of (a) the formation of the gaps, (b) the nondistractive determination of the depths of the gap in the lighted FL tubes, and (c) the influence of the gaps to the illuminance $\left(\mathrm{lm} \mathrm{m}^{-2}\right)$ from the phosphor screen of the lighted FL tubes.

\section{Experiments}

First we had the study on the residual gases in the vacuum-sealed glass tubes alone. We took the glass tubes in the outer diameters in $5 \times 10^{-3} \mathrm{~m}$ of the borosilicate glass tubes for the studies where generate the residual gases in the vacuum-sealed glass tubes in the production process of the FL tubes. The testing borosilicate glass tubes contain neither (a) metal electrodes, nor (b) Ar gas and (c) the phosphor screen. After the confirmation which the production process generates the residual gases in the vacuum-sealed glass tube, we had studied the glass tubes that contained (d) the Ar gases, (e) the W-filament coils with the $\mathrm{BaO}$ particles. Finally, we had studied (f) the FL tubes with the phosphor screen that is the opaque screen for the naked eyes. The study on the depths of the gap in the lighted FL tubes requires the nondestructive determinations of the gaps in the lighted FL tubes. We had found that the depths of the gap could be quantitatively determined by the measurements of the build-up curve of the illuminance $(\mathrm{lm})$ of the lighted FL tubes in the given Ulbricht Sphere. We took the illuminance $(\mathrm{lm})$ on the control panel of the Ulbricht Sphere. The number of the evaporated $\mathrm{Hg}$ atoms in the heated Ar gas space in the gap has quantitatively calculated for the clarification as the optical filter to the UV lights from the positive column. Finally we had determined the depths of the gap from the build-up curves of the illuminance of the commercial $40 \mathrm{~W}-\mathrm{HCFL}$ tubes from the various FL producers.

\section{Results and Discussions}

We like to clarify the word of "positive column". The volume of the constant light-intensity in the Ar gas space of the lighted FL tubes has traditionally named as "positive column" [7]. The volume (column) of the constant lighted area is not formed by the positive charges. The particles in the positive column are the mixture of $\mathrm{Ar}^{1+}$, free electrons, $\mathrm{Ar}^{*}$, and $\mathrm{Ar}$ atoms. It is sure that the electrons from the cathode move on in the superconductive vacuum between Ar atoms in the Ar gas space $\left(F_{\text {vect }} \geq F_{\text {phos }}\right)$ that is the positive column. The anode collects the arrived electrons from the vacuum. We cannot find out a proper word. We take the word of "positive column" for the lighted volume in the Ar gas space in this report. In this report, we do not discuss the details of the structure of the positive column. We discuss here the diameter of the positive column which is formed by the $10^{15}$ moving electrons in the Ar gas space $\left(\mathrm{F}_{\text {vect }} \geq \mathrm{F}_{\text {phos }}\right)$ [2]. We also discuss about determined illuminance $\left(1 \mathrm{~m} \mathrm{~m}^{-2}\right)$ from the phosphor screen that is seriously influenced by the depths of the gap.

\subsection{Vacuum-Sealed Glass Tubes Contaminated with Residual Gases}

The study started from the presence of the residual gases in the vacuum-sealed glass tubes. The studies of the CRT and vacuum (radio) tubes had disambiguated the residual gases. Followings are the experiments with the glass tubes alone.

The experiments were made by the borosilicate glass tubes 
in $4 \times 10^{-3} \mathrm{~m}$ diameter. The glass tubes did not have neither the electrode, nor Ar gas, and phosphor screen. The borosilicate glass tubes had pumped out on the ordinary pumping facilities for the FL tube production. After degassing process from the glass tubes at $550^{\circ} \mathrm{C}$ for one hour, the vacuum pressure of the control panel of the pumping facilities indicated $7 \times 10^{-3} \mathrm{~Pa}(=$ $5 \times 10^{-5}$ Torr). The low vacuum pressure had confirmed by a Tesla-Coil on the pumped glass tubes on the pumping facilities. No light detected from the degassed borosilicate glass tube on the pumping facilities. After the sealed-off of the glass tubes from the pumping facilities by the melt-down of the pumped glass tubes, the vacuum sealed glass tubes emitted the brilliant bluish-white lights under the Tesla-coil. The lighted gases are mainly $\mathrm{CO}_{2}, \mathrm{H}_{2} \mathrm{O}$, air $\left(\mathrm{N}_{2}\right.$ and $\left.\mathrm{O}_{2}\right)$ and others. Figure 1 shows photograph of the lighted three vacuum-sealed glass tubes under the Tesla-Coil. Each tube emits slightly different colors. As shown in the photograph in Figure 1, the vacuum-sealed glass tubes contain a large amount of the residual gases. The estimated gas pressures of the residual gases from the light intensities are the around $300 \mathrm{~Pa}$ (= a few Torr). The residual gases in the vacuum-sealed glass tubes come from the melt-down of the pumped glass tubes for the vacuum-seal of the pumped glass tube. The residual gases do not come from the inner wall of the testing glass tubes.

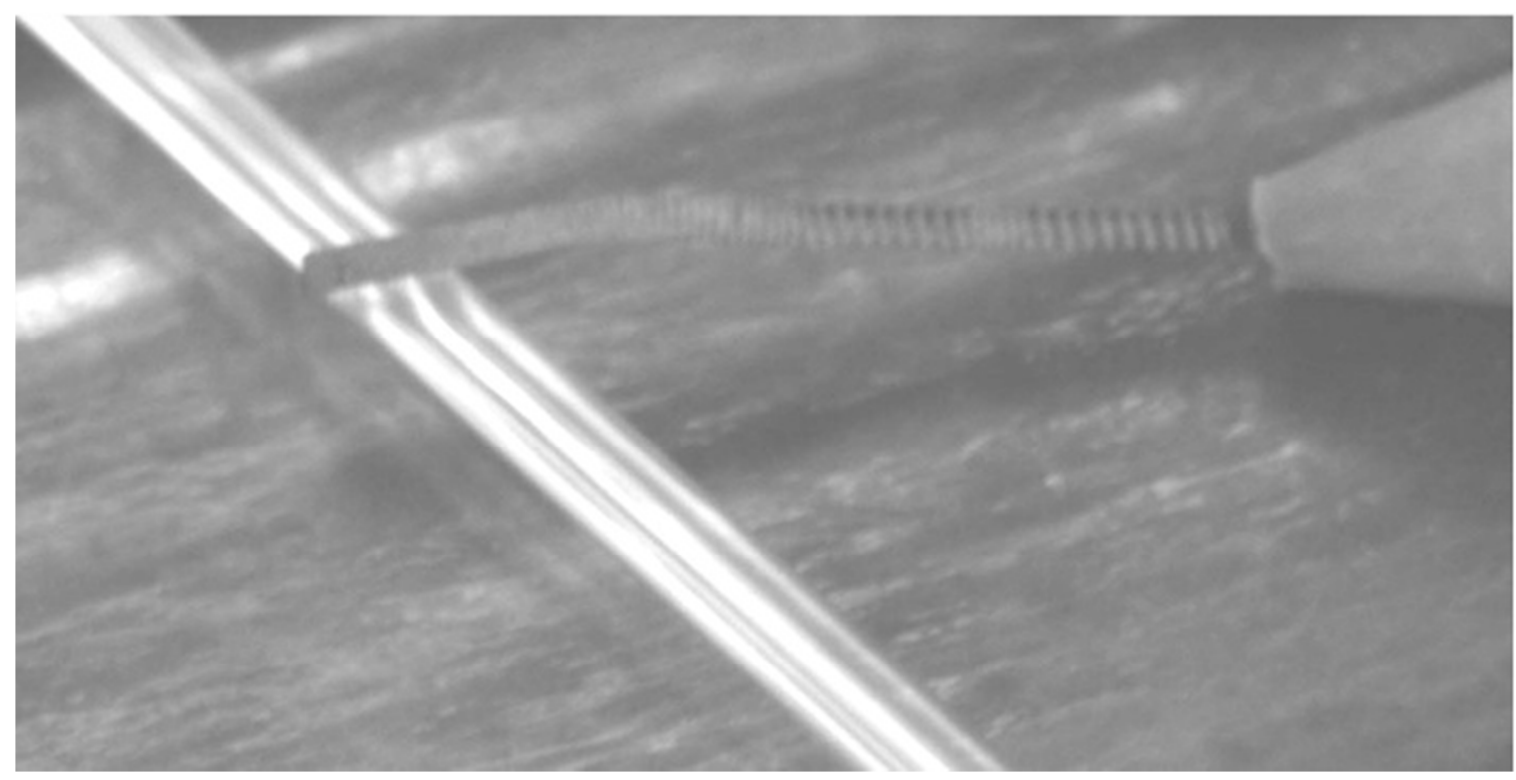

Figure 1. Photograph of emitted vacuum-sealed borosilicate glass tubes under Tesla-coil.

Then we had observed a very interesting happing with the lighted vacuum-sealed glass tubes. After one over night, the glass tubes did not emit the light anymore under the Tesla-Coil The vacuum-sealed glass tubes had the vacuum pressure less than $10^{-2} \mathrm{~Pa}\left(=10^{-4}\right.$ Torr $)$ after one over night. The degassed cavities in the inner surface volume of the glass tubes slowly, but surely, adsorb the residual gases. The surface of the inner glass tubes were contaminated with the adsorbed gases. As the unlighted glass tubes heat at $100^{\circ} \mathrm{C}$ for 60 minutes, the glass tubes light again under the Tesla-Coil. The lights in the glass tube disappear again by the overnight.

The similar results were also obtained with the sodium-lime glass tubes in the outer diameter of $1.3 \times 10^{-2} \mathrm{~m}$. The glass tubes had the degassing process at $350^{\circ} \mathrm{C}$ for 60 minutes. The detected temperature was not the furnace temperature. The temperature was detected on the surface of the glass tubes. The glass tubes are good thermal insulator. The glass tubes on the pumping facility did not light under the Tesla-Coil. The vacuum-sealed glass tubes emitted the bluish-white lights under the Tesla-Coil. After one overnight, the lights disappeared from the vacuum-sealed sodium-lime glass tubes.

From the above experiments, it may say that the currently produced FL tubes are heavily contaminated with the released gases from the seal-off of the pumping glass tube by the melt-down twice, independent on the kinds of the glass tubes and vacuum pumps used. The acceptable FL tubes can produced with the sodium-lime glass tubes. The use of the borosilicate glass tubes is unnecessary for the FL tubes. The purpose of the degassing process of the FL glass tubes is the removal of the adsorbed gases in the cavities in the surface volume of the glass tubes. The adsorbed gases in the cavities in the inner surface volume of the glass tubes degas at around $350^{\circ} \mathrm{C}$. Above $400^{\circ} \mathrm{C}$, the trapped gases in the cavities in the bulk of the glass tubes slowly diffuse out from the inner glass wall up to the melting temperature. In the FL tube production, the out-diffusion from the bulk glass is not necessary. The most important concern is the degassing of the trapped gases from the cavities in the inner surface volume of the glass tube. The glass is a good thermal insulator. The degassing from the cavities in the surface volume requires the heating times longer than 40 minutes at the given temperature. The determined temperature is not the furnace temperature on the control panel. The temperature is the glass tubes.

The cavities in the surface volume of the vacuum-sealed glass tubes slowly adsorb the residual gases. As the glass tubes heat up above $80^{\circ} \mathrm{C}$, the cavities slowly release the adsorbed gases to the vacuum-sealed glass tube.

From the experimental results, it can say that the generation 
source of the residual gases in the vacuum-sealed glass tubes is the vacuum-sealing process of the pumping tube by the melt-down. The residual gases in the vacuum-sealed glass tubes do not change by the degassing process at above $350^{\circ} \mathrm{C}$ and kinds of the facilities of the diffusion pumps. The cavities in the surface volume of the vacuum-sealed glass tubes adsorb and release the residual gases with the temperatures of the vacuum-sealed glass tubes. The vacuum sealed glass tubes contain the residual gases in the cavities in the surface volume of the inner glass tubes.

\subsection{Diameter of Positive Column in Vacuum-Sealed Glass Tubes}

We step in the study of the moving electrons in the positive column of the vacuum-sealed glass tubes. The vacuum-sealed glass tubes must contain $\mathrm{Ar}$ gas and electrodes for the operation of the vacuum-sealed glass tubes. The electrons from the cathode move on in the superconductive vacuum in the Ar gas. We may detect the influence of the adsorbed gases in the cavities to the moving electrons.

We took the glass tubes that the outer diameter was $1.0 \mathrm{x}$ $10^{-2} \mathrm{~m}$, and the inner diameter was $9 \times 10^{-3} \mathrm{~m}$. The examined glass tubes contain the $\mathrm{W}$-filament coils with the $\mathrm{BaO}$ particles and $\mathrm{Ar}$ gas pressure at $665 \mathrm{~Pa}$ (= 5 Torr), without $\mathrm{Hg}$ droplets and phosphor screen. The glass tubes emit the sky-blue lights from the excited Ar atoms (Ar*). We had studied the diameters of the positive column that contains the moving electrons in the Ar gas space.

If someone observes the lighted glass tube by the naked eyes, he may observe the sky-blue lights in the entire volume of the glass tube. There should be the gap between positive column and inner glass wall. The positive column generates the strong lights. The strong lights from the positive column are multiple reflections on the surface of the inner glass wall ( $\sim 8 \%$ reflectance each time) before the penetration through the glass wall (92\% transmission). The gap fills up with the strong lights that are the multiple reflections on the surface of the inner glass wall. The eyes have the response curve of S-shape to the light intensities. The light intensities of the multiple reflections in the gap are in the upper saturation range of the S-curve of the eye's sensitivity. The lights of the multiple reflections had optically removed from the observed lights. The removal of the lights of the multiple reflections is achieved by an insertion of the optically neutral-filter $(5 \%$ transmission) between the glass tube and eyes. You may certainly detect the real diameter of the positive column in the lighted glass tube. The same story is applicable to the photosensitive film of the camera. As the photograph of the lighted glass tube is taken by a low dose of the camera, we have the photograph shown in Figure 2.

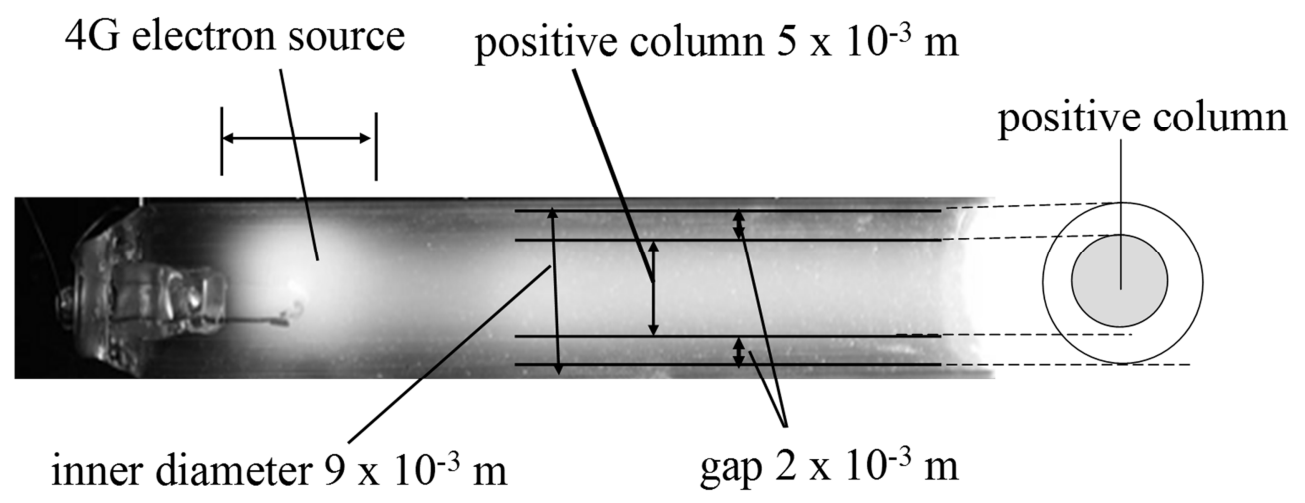

Figure 2. Determined positive column in lighted FL glass tube with Ar gas only. Photograph is made with a low exposure dose of the camera.

The results indicate that the adsorbed gases in the cavities in the surface volume of the FL glass tubes at room temperature have the negative charges. The negative charges push back the approaching electrons to the center volume of the Ar gas space by the Coulomb's repulsion. We have determined the diameter of the positive column as $5 \times 10^{-3} \mathrm{~m}$ with the gap of $2 \times 10^{-3} \mathrm{~m}$ depth. Following calculations are made with the glass tubes.

The calculations are made with the unit length $(0.01 \mathrm{~m}=1$ $\mathrm{cm})$ of the glass tube for the generalization. The volume of the Ar gas space per unit length of the glass tube $\left(\mathrm{V}_{\mathrm{Ar}}\right)$ is calculated as $\mathrm{V}_{\mathrm{Ar}}=6.3 \times 10^{-7} \mathrm{~m}^{3}\left(=\pi \mathrm{r}^{2} \mathrm{~m}^{2} \times 1 \times 10^{-2} \mathrm{~m}=\pi \varphi^{2}\right.$ $4^{-1} \times 10^{-2} \mathrm{~m}^{3}=0.78 \times\left(9 \times 10^{-3}\right)^{2} \times 10^{-2} \mathrm{~m}^{-3}=0.78 \times 81 \times 10^{-8}$ $\left.\mathrm{m}^{3}\right)$, where $\mathrm{r}$ is inner radius and $\varphi$ is inner diameter $(2 \mathrm{r}=\varphi)$ of the glass tube. The depth of the gap between positive column and inner glass wall of the glass tube is $2 \times 10^{-3} \mathrm{~m}\{=(9-5) \times$

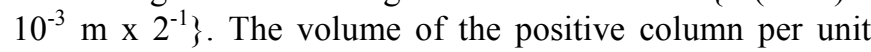
length $\left(\mathrm{V}_{\text {posi }}\right)$ of the lighted glass tube is calculated as $\mathrm{V}_{\text {posi }}=$
$1.9 \times 10^{-7} \mathrm{~m}^{3}\left\{=0.78 \times\left(5 \times 10^{-3}\right)^{2} \times 10^{-2} \mathrm{~m}^{3}\right\}$. The ratio of $\mathrm{V}_{\text {posi }}$ to $\mathrm{V}_{\mathrm{Ar}}$ is $0.30\left(=1.9 \times 6.3^{-1}\right)$. The volume of the gap per unit length $\left(\mathrm{V}_{\text {gap }}\right)$ of the glass tube is calculated as $4.4 \times 10^{-7} \mathrm{~m}^{3}$ $\left\{=\mathrm{V}_{\mathrm{Ar}}-\mathrm{V}_{\text {pos }}=(6.3-1.9) \times 10^{-7} \mathrm{~m}^{3}\right)$. The ratio of $\mathrm{V}_{\text {gap }}$ to $\mathrm{V}_{\mathrm{Ar}}$ is $0.70(=4.4 / 6.3)$. The calculated results summarize in Table 1. The $\mathrm{F}_{\text {gas }}$ determines the depth of the gaps and the diameters of the positive column. The $F_{\text {gas }}$ is the electric field from the adsorbed residual gases in the cavities in the surface volume of the inner glass tube.

The calculated results of the volumes of the positive column and gap in Table 1 give a surprise for us. At a glance of the photograph of Figure 2 by the naked eyes, the lighted positive column in the glass tube looks like a large volume in the lighted glass tube. In reality, the volume of the lighted positive column is only $30 \%$ volume of total Ar gas space. The electrons move on in the $30 \%$ Ar gas space of the $\mathrm{V}_{\mathrm{Ar}}$. The lights generate in the Ar gas space in the inside of the positive 
column. The gap contains $70 \%$ volume of the Ar gas space in the lighted glass tube. The moving electrons cannot step in the gap by the Coulomb's repulsion from the $\mathrm{F}_{\text {gas }}$ on the inner glass wall.

Table 1. Calculated volumes of Ar gas space $V_{A r}$, positive column $V_{\text {posi }}$, and gap $V_{\text {gap }}$ in examined lighted glass tube (outer diameter $0.010 \mathrm{~m}$ ) by electric field $F_{\text {gas }}$ in lighted glass tube in $9 \times 10^{-3}$ m inner diameter

\begin{tabular}{|c|c|c|c|c|c|}
\hline $\begin{array}{l}\varphi_{\text {out }} \\
\left(\times 10^{-3} \mathrm{~m}\right)\end{array}$ & $\begin{array}{l}\varphi_{\text {in }} \\
\left(\times 10^{-3} \mathrm{~m}\right) \\
\end{array}$ & $\begin{array}{l}\varphi_{\text {posi }} \\
\left(\times 10^{-3} \mathrm{~m}\right) \\
\end{array}$ & $\begin{array}{l}V_{\mathrm{Ar}} \\
\left(\times 10^{-6} \mathrm{~m}^{3}\right)\end{array}$ & $\begin{array}{l}V_{\text {posi }} \\
\left(\times 10^{-6} \mathrm{~m}^{3}\right) \\
\end{array}$ & $\begin{array}{l}V_{\text {gap }} \\
\left(\times 10^{-6} \mathrm{~m}^{3}\right)\end{array}$ \\
\hline 10 & 9 & 5 & 0.63 & 0.19 & 0.44 \\
\hline- & - & - & $100 \%$ & $30 \%$ & $70 \%$ \\
\hline
\end{tabular}

The results in Table 1 did not change with the addition of the $\mathrm{Hg}$ droplets in the glass tubes with the reason that the excited $\mathrm{Hg}$ atoms $\left(\mathrm{Hg}^{*}\right)$ emit the invisible UV lights. We assume that the evaporated $\mathrm{Hg}$ atoms uniformly distribute in the entire Ar gas space. The Ar gas in the gap contains $70 \%$ unexcited $\mathrm{Hg}$ atoms. The unexcited $\mathrm{Hg}$ atoms in the gap optically absorb the UV lights emitted in the positive column. The emitted $254 \mathrm{~nm}$ and $183 \mathrm{~nm}$ UV lights are respectively assigned as the electron transitions between the excited $6^{3} \mathrm{p}_{1}$ and $6^{1} \mathrm{p}_{1}$ to the grand state $6^{1} \mathrm{~s}_{0}$. The unexcited $\mathrm{Hg}$ atoms fill up the electrons in the grand state $6^{1} \mathrm{~s}_{0}$. The unexcited $\mathrm{Hg}$ atoms in the gap efficiently absorb the UV lights, which terminate to the grand state $6^{1} \mathrm{~s}_{0}$, with the resonance absorption. The positive column contains only $30 \%$ of the evaporated $\mathrm{Hg}$ atoms. The unexcited $70 \% \mathrm{Hg}$ atoms in the gap optically absorb the UV lights from the positive column. The Ar gas space in the gap works as the optical filter for the UV lights from the positive column. The gap absorbs $21 \%(0.3 \times 0.7=$ 0.21.) of the emitted UV lights in the positive column. The UV lights that penetrate through the gap corresponds to $9 \%(=30 \%$ $-21 \%$ ) of the total evaporated $\mathrm{Hg}$ atoms in the Ar gas space in the lighted glass tubes. The experiments described above do not have a difficult for the duplication.

As described in (3-1), the cavities in the surface volume of the vacuum-sealed glass tubes hold the residual gases. The cavities release the trapped residual gases to the $\mathrm{Ar}$ gas space as the glass tubes heated at the above $80^{\circ} \mathrm{C}$. The positive column in the heated glass tubes extents to the glass wall. The released residual gases from the cavities do not influence to the moving electrons in the Ar gas space. The released gases distribute in the Ar gas space that has the $2 \times 10^{-7} \mathrm{~m}$ separation distance. The Ar gas pressure is $665 \mathrm{~Pa}$. The gas pressure of the residual gases is below $300 \mathrm{~Pa}$. The released residual gases in the Ar gas space have the chemical reaction that composes the methane. The methane gas polymerizes to hydrocarbons $\left(\mathrm{CH}_{\mathrm{n}}\right)$ in a high number of hydrogen under the moving electrons.

\subsection{Diameters of Positive Column of FL Tubes}

The phosphor screens in CRT and FL tube have the electric charges $[8,9,10]$. The phosphor screens for the CRTs emit the cathodoluminescence (CL) and the phosphor screens for the FL tubes emit the photoluminescence (PL). The large difference between the CL and PL are the mechanisms of the luminescence. The CL phosphors emit the lights by the recombinations of the pairs of the electrons and holes at the luminescence centers. The pairs of the electrons and holes in the phosphor particles are generated by the incident electrons in the phosphor particles [8]. The penetration of the incident electrons $(10 \mathrm{kV})$ into the phosphor particles is disturbed by the electric charges on the phosphor screen. The sharp images on the phosphor screen in CRT are made with the clean surface of the phosphor particles chemically and physically.

On the other hand, the PL phosphors emit the lights by the direct excitation of the luminescence centers by the UV lights. The large difference between CL and PL phosphors is the surface charges on the phosphor particles. The UV lights are the photons that do not have the electric charge. The best PL phosphor particles are contaminated with the electric charges. If the phosphor screen of the FL tube is made with the CL phosphor screen, the FL tube emits a dim light from the phosphor screen $[8,9]$. We are studying of the FL tubes that the phosphor screens are contaminated with the electric charges.

The inner wall of the lighted FL tubes is covered with the opaque phosphor screen. Unfortunately, we cannot observe the inside of the lighted FL tubes. Accordingly, we cannot directly determine the depths of the gap between positive column and phosphor screen in the lighted FL tubes with the opaque phosphor screen. Fortunately, the results in the previous section 3-2 inform us the depth of the gap between positive column and phosphor screen in the lighted FL tubes may evaluate with the ratios of $\left\{\mathrm{V}_{\mathrm{pos}} \mathrm{x}\left(\mathrm{V}_{\mathrm{Ar}}\right)^{-1}\right\}$. The depths of the gap do not change with the change in the diameters of the FL tubes. We may calculate the ratios of $\left\{\mathrm{V}_{\mathrm{pos}} \mathrm{x}\left(\mathrm{V}_{\mathrm{Ar}}\right)^{-1}\right\}$ with the various depths of the gap as the function of the diameters of the FL tubes.

Figure 3 shows the calculated ratios of $\left[\mathrm{V}_{\text {posi }} \times\left(\mathrm{V}_{\mathrm{Ar}}\right)^{-1}\right]$ of the FL tubes in the various diameters $\left(\mathrm{x} 10^{-2} \mathrm{~m}\right)$. The parameter is the depths of the gap that are $0.5,1,2,3$, and $4\left(\mathrm{x} 10^{-3} \mathrm{~m}\right)$ from the phosphor screen. The curves in Figure 3 give the important information of the phosphor screen. It has empirically found that the ratios of $\left[\mathrm{V}_{\text {posi }} \times\left(\mathrm{V}_{\mathrm{Ar}}\right)^{-1}\right]$ sharply decrease with the narrow diameters of the FL tubes. The FL tubes in the narrow diameter are made with the phosphor screen that is the blend mixture of the CL phosphor and PL phosphors for the reduction of the depth of the gap. The blend ratio for the FL tubes had been empirically determined. The practical HCFL tubes before 1975 were produced with the phosphor screen of $\mathrm{Ca}_{3}\left(\mathrm{PO}_{4}\right)_{4}(\mathrm{~F}, \mathrm{Cl}): \mathrm{Sb} ; \mathrm{Mn}$ white emitting phosphor powder. The diameter of the practical HCFL tubes is empirically determined as $3.2 \times 10^{-2} \mathrm{~m}(\mathrm{~T}-10)$. The $\left[\mathrm{V}_{\text {posi }} \mathrm{x}\right.$ $\left(\mathrm{V}_{\mathrm{Ar}}\right)^{-1}$ ] curves of the commercial HCFL tubes approach to the constant value as the diameters of the FL tubes are wider than 
$3 \times 10^{-2} \mathrm{~m}$. We may analyze the reason of the constant value of the $\left[\mathrm{V}_{\text {posi }} \times\left(\mathrm{V}_{\mathrm{Ar}}\right)^{-1}\right]$ with the diameters wider than $3 \times 10^{-2} \mathrm{~m}$.

The active AC power consumption $\left(\mathrm{W}_{\text {tube }}\right)$ of the external AC circuit had considered for the determination of the optimal diameter of the FL tubes [3]. The $\mathrm{W}_{\text {tube }}$ is the linear function of the capacitor $\mathrm{C}_{\text {tube, }}$ which is formed with the $\mathrm{Ar}^{1+}$ in the Ar gas space in the lighted FL tubes [3]. The capacitance of the $\mathrm{C}_{\text {tube }}$ increases with the square of the diameters of the FL tubes. The compromised optimal diameter of the commercial 40W-HCFL tubes had been determined as $3.2 \times 10^{-2} \mathrm{~m}$ (T-10) that corresponds to the $\left[\mathrm{V}_{\text {posi }} \times\left(\mathrm{V}_{\mathrm{Ar}}\right)^{-1}\right]$ curves of the depth of the gaps in $3 \times 10^{-3} \mathrm{~m}$ in Figure 3 . Hence we have found a subject that is the possibility of the improvement of the luminance of the commercial $40 \mathrm{~W}-\mathrm{HCFL}$ tubes in the diameter of $3.2 \times 10^{-2}$ $\mathrm{m}$. From the analysis of the results in Figure 3, it has found a breakthrough in the study of the lighted FL tubes. The illuminance $\left(1 \mathrm{~m} \mathrm{~m} \mathrm{~m}^{-2}\right)$ of the present HCFL tubes may significantly improve by the reduction of the depths of the gap between positive column and phosphor screen. The improvement is not the several \% that are the engineering works. The improvement may be more than double of the illuminance $\left(\mathrm{lm} \mathrm{m}^{-2}\right)$ of the present HCFL tubes.

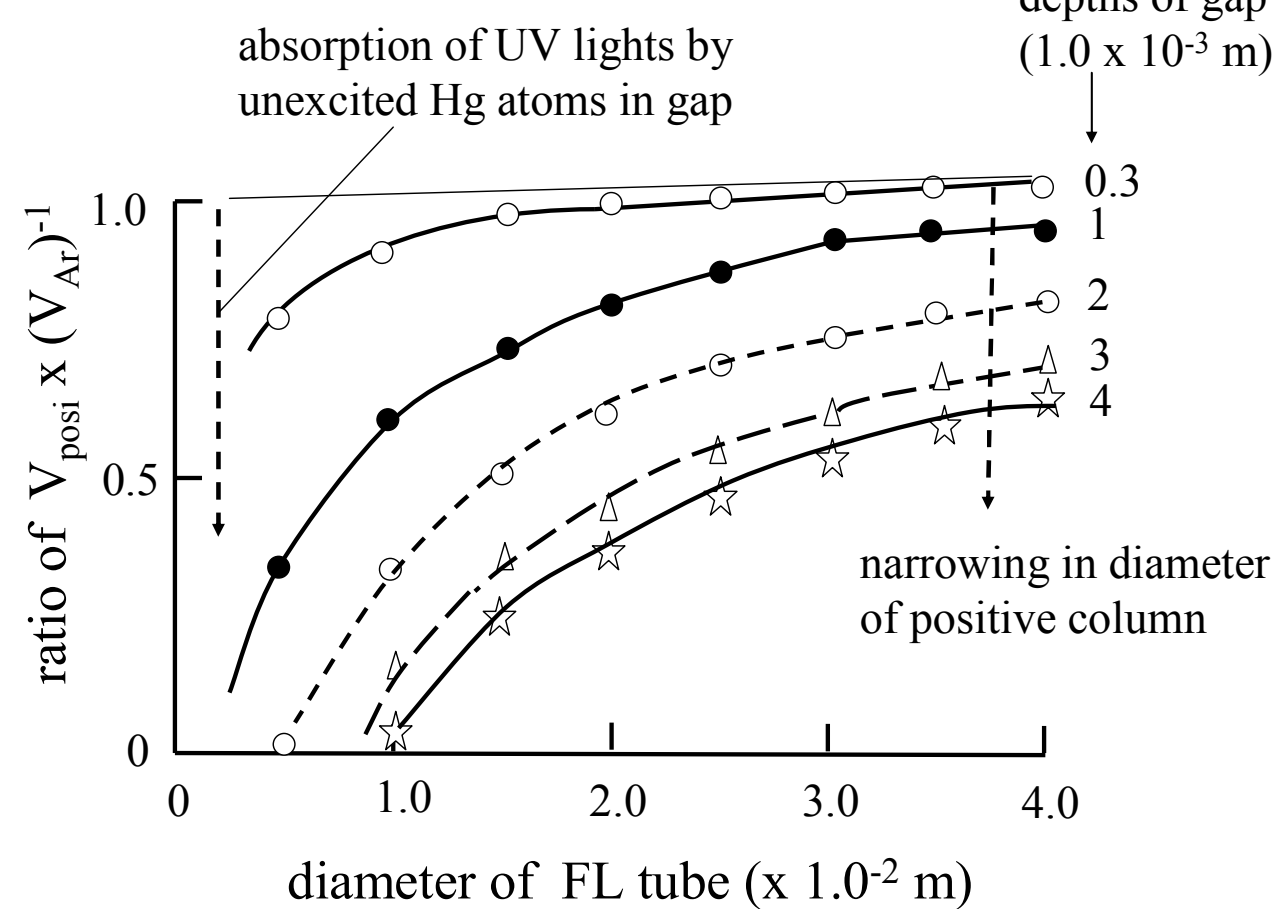

Figure 3. Calculated ratio of $\left[V_{p o s} x\left(V_{A r}\right)^{-1}\right]$ of FL tubes as a function of diameters of glass tube $(x 0.01 \mathrm{~m})$. Parameter is depth of gaps $\left(1 \times 10^{-3} \mathrm{~m}\right)$ between positive column and phosphor screen.

\subsection{Non-Distractive Analysis of Mechanisms of Illuminance of FL Tubes}

The light intensity from the lighted FL tubes corresponds to the numbers of the evaporated $\mathrm{Hg}$ atoms in the heated Ar gas space in the positive column. The heat source of the lighted FL tubes is solely ionization of the Ar atoms by the moving electrons in the positive column. The ionization of Ar atoms $\left(\mathrm{Ar}^{1+}\right)$ releases the heat by the change in the entropy. The Ar gas is the good thermal insulator $\left\{1.8 \times 10^{-3} \mathrm{~W} \times\left(\mathrm{m}{ }^{0} \mathrm{~K}\right)^{-1}\right\}$. The positive column is thermally shielded by the Ar gas in the gap. The number of the evaporated $\mathrm{Hg}$ atoms in the positive column slowly increase by the evaporation from the $\mathrm{Hg}$ droplets on the phosphor screen. The intensities of the UV lights from the positive column are proportionate to the number of the evaporated $\mathrm{Hg}$ atoms in the positive column. Consequently, the lights from the phosphor screen rise up with running time after the power-on. The light intensity from the FL tube has the build-up curve with the operation time of the FL tube.
We have taken the commercial $40 \mathrm{~W}-\mathrm{HCFL}$ tube that has selected as the best HCFL tube for the measurement of the build-up curve of the illuminance $(\mathrm{lm})$ on the control panel of the Ulbricht Sphere. The commercial 40W-HCFL tubes have the depth of the gap is around $3 \times 10^{-3} \mathrm{~m}$ with the thin phosphor screen of the blend mixture of the tri-color rare-earth phosphor powders. The $\mathrm{Hg}$ droplets on the phosphor screen are slowly heat up by the thermal radiation from the positive column. Accordingly, the illuminance $(\mathrm{lm})$ of the commercial 40W-HCFL tubes has the build-up curve in the Ulbricht Sphere. Figure 4 shows, as the example, the build-up curve of the selected 40W-HCFL tubes (T-10) with the phosphor screen of the blend mixture of the tri-color rare earth phosphor power. The temperature of the positive column of the 40W-HCFL tube can be determined by the infrared thermometer. The determined temperature of the positive column was $35 \pm 5^{\circ} \mathrm{C}$.

The temperature of the measurement room was $20^{\circ} \mathrm{C}$ that give the $\mathrm{Hg}$ vapor pressure at $9 \times 10^{-2} \mathrm{~Pa}\left(=7 \times 10^{-4}\right.$ Torr $)$ [11]. The starting illuminance $(\mathrm{lm})$ of the build-up curve in the given Ulbricht Sphere is 6.2 of the arbitrary scale on the 
control panel. The saturated illuminance of the build-up curve is 14.5 that is 2.3 times of the starting illuminance $(=14.5 / 6.2)$. The $\mathrm{Hg}$ pressure in the positive column at the saturated illuminance is simply calculated as $0.21 \mathrm{~Pa}\left(=9 \times 10^{-2} \mathrm{~Pa} \times 2.3\right)$ $\left(=1.6 \times 10^{-3}\right.$ Torr $)$. The $\mathrm{V}_{\mathrm{Ar}}$ in unit length is $7.0 \times 10^{-4} \mathrm{~m}^{3}\{=$ $0.78 \times\left(3 \times 10^{-2}\right)^{2}$ \} and $\mathrm{V}_{\text {posi }}$ in the unit length is $4.5 \times 10^{-4} \mathrm{~m}^{3}$ $\left\{=0.78 \times\left(2.4 \times 10^{-2}\right)^{2}\right\}$. The $\mathrm{V}_{\text {gap }}$ is $2.5 \times 10^{-4} \mathrm{~m}^{3}\{=(7.0-4.5)$ $\left.\times 10^{-4} \mathrm{~m}^{3}\right\}$. The ratio of $\left(\mathrm{V}_{\text {posi }} \times \mathrm{V}_{\mathrm{Ar}}^{-1}\right)$ is $0.64\left(=0.9 \times 1.4^{-1}\right)$. The ratio of $\left(\mathrm{V}_{\text {gap }} \times \mathrm{V}_{\text {posi }}{ }^{-1}\right)$ is $0.56\left(=2.5 \times 4.5^{-1}\right)$. The unexcited $\mathrm{Hg}$ atoms in the gap absorb a $56 \%$ of the UV lights from the positive column. By the consideration of the absorption of the UV lights by the gap, the actually excited $\mathrm{Hg}$ atoms in the positive column is given by 2.1 times $\{=(1-0.56$ $\left.=0.44) \times 0.21^{-1}\right)$. The excited $\mathrm{Hg}$ atoms in the positive column is calculated as $0.44 \mathrm{~Pa}(=0.21 \mathrm{~Pa} \times 2.1)\left(=3.3 \times 10^{-3}\right.$ Torr $)$. The calculated $\mathrm{Hg}$ atoms $(0.44 \mathrm{~Pa})$ in the positive column of the commercial $40 \mathrm{~W}-\mathrm{HCFL}$ tube close enough to the $\mathrm{Hg}$ vapor pressure $0.53 \mathrm{~Pa}\left(=4 \times 10^{-3}\right.$ Torr $)$ at $35^{\circ} \mathrm{C}$ in the Handbook of Physics and Chemistry [11].

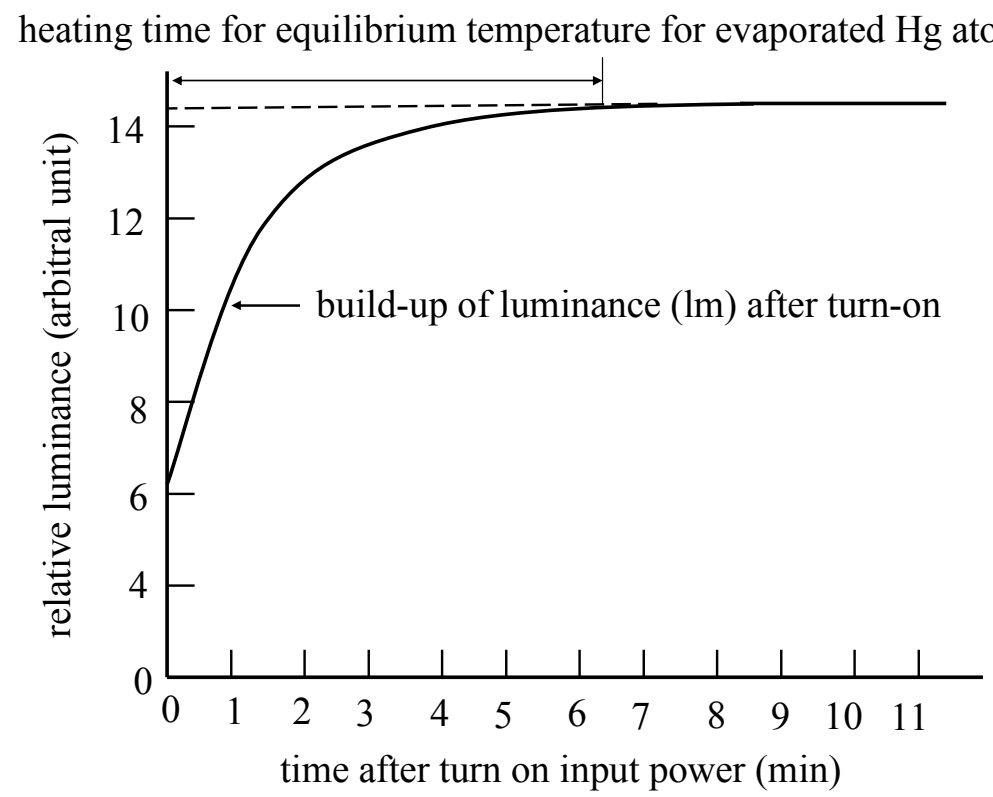

Figure 4. Build-up curve of luminance of commercial 40W-HCFL tube with phosphor screen of the blend mixture of tri-color rare earth phosphor screen with 1 $x 10^{-3} \mathrm{~m}$ gap.

If you may reduce the depth of the gap to $3 \times 10^{-4} \mathrm{~m}$ from 3 $\mathrm{x} 10^{-3} \mathrm{~m}$, the $\mathrm{V}_{\text {posi }}$ is $6.5 \times 10^{-4} \mathrm{~m}^{3}\left\{=0.78 \times\left(2.9 \times 10^{-2} \mathrm{~m}\right)^{2} \mathrm{x}\right.$ $1 \mathrm{~m}\}$. The $\left(\mathrm{V}_{\text {posi }} \times \mathrm{V}_{\mathrm{Ar}}^{-1}\right)$ is 0.92 . The number of the evaporated $\mathrm{Hg}$ atoms in the positive column of the lighted FL tube increases to 1.4 times $\left(0.92 \times 0.64^{-1}\right)$. The gap has a negligibly small depth. The light intensity of the lighted FL tube will increase to 2.5 times $\left(=1.4 \times 0.56^{-1}\right)$ of the present light intensity. The calculations indicate the interesting subject for the reduction of the depth of the gap in the lighted 40W-HCFL tubes. The systematic study of the reduction of the depth of the gap remains as a future study.

We have found a new tool for the determination of the evaporated $\mathrm{Hg}$ atoms in the positive column of the lighted FL tubes. The new tool is the build-up curves of the illuminance (lm) of the Ulbricht Sphere. The amount of the evaporated $\mathrm{Hg}$ atoms in the positive column determines the UV light intensities. The temperature of the Ar gas space in the positive column determines the number of the evaporated $\mathrm{Hg}$ atoms in the Ar gas space in the lighted FL tubes. The output of the lights from the phosphor screen of the lighted FL tubes is significantly reduced by the optical absorption of the UV lights by the unexcited $\mathrm{Hg}$ atoms in the gap. The reduction of the depth of the gap in the lighted FL tubes involves in the solid-state physics of the phosphor particles in the average size of $4 \times 10^{-6} \mathrm{~m}$. The number of the evaporated $\mathrm{Hg}$ atoms in the positive column is determined by the temperature of the positive column. Since the phosphor screen is a transparent for the infrared lights, the infrared thermometer may detect the temperature of the positive column in the lighted FL tubes. By the measurements of the build-up curve of the illuminance ( $\mathrm{lm}$ ) on the control panel of the Ulbricht Sphere, you may obtain the quantitative data of (a) the number of the lighted $\mathrm{Hg}$ atoms in the positive column, and (b) the significant loss of the lighted UV lights by the optical filter of the depths of the gap. Those are the new tools for the study on the lighted FL tubes. I hope you may remarkably improve the illuminance $\left(\mathrm{lm} \mathrm{m}^{-2}\right)$ of the lighted FL tubes by the study with the new tools.

Traditionally, the Ulbricht Sphere has used for the determination of the invalided luminous efficiency $\left(\mathrm{lm} \mathrm{W}^{-1}\right)$, which conceals the reality of the lighting mechanisms of the lighted FL tube. The Ulbricht Sphere never uses for the determination of the invalided luminous efficiency $\left(1 \mathrm{~m} \mathrm{~W}^{-1}\right)$. So far as the Ulbricht Sphere is used for the determination of the build-up curve of the illuminance ( $\mathrm{lm}$ ), you may have a direction of the study on the lighted FL tubes. The FL tubes hold the unrivaled lighting sources with the astronomical quantum efficiency $\eta_{\mathrm{q}}=10^{13}$ photons (volume of Ar gas $\mathrm{m}^{3}$, $s)^{-1}$ from the phosphor screen. The solid lighting sources have 
the $\eta_{\mathrm{q}}$ smaller than 1.0.

The solid lighting devices, like as the LED lamp, emit one photon with the injection of the two electrons. The energy efficiency for the generation of the lights of the solid lighting source is $50 \%$ maximum. The energy conversion efficiency of the commercial LED lamps is between $20 \%$ and $30 \%$ with the different AC operation circuits [1]. On the other hand, the FL tubes are operated with the coexistence of the disparities of the external AC driving circuit and internal DC electric circuit [3]. The active AC power consumption, $\mathrm{W}_{\text {act }}$, of the external AC driving circuit is not related with the generation energy of the lights. The lights are generated by the internal DC electric circuit [2]. The power consumption of the internal DC electric circuit is $0.02 \mathrm{~W}$ that is negligibly small energy. If the external AC driving circuit is substituted with the external DC electric circuit, the $\mathrm{W}_{\text {act }}$ will down to nearly zero [2]. The FL tubes (T-10) may emit the $10^{25}$ photons per second from the phosphor screen under the external DC electric circuit $[1,2]$. Hence, the FL tubes may hold the unrivaled advantage as the lighting source over the solid lighting sources.

\subsection{Examples of Build-up Curves of Commercial FL Tubes}

Here is the practical problem. The great latent advantage of the FL tubes has concealed by the evaluation of the invalided luminance efficiency $\left(1 \mathrm{~m} \mathrm{~W}^{-1}\right)$ for more than 80 years. Figure 5 shows the build-up curves of the commercial 40W-HCFL tubes that are produced by the different FL producers. The build-up curves in Figure 5 show that the depths of the gap in the commercial 40W-HCFL tubes do not have the control by the FL producers. We also detected the variation in the build-up curves of the 40W-HCFL tubes with the same producers. This is because they use the Ulbricht Sphere with the wrong way that is the invalided luminance efficiency $(\mathrm{lm}$ $\mathrm{W}^{-1}$ ). We like to suggest you for the measurements of the build-up curves of the illuminance $(\mathrm{lm})$ for the quality control of the depths of the gap in the produced HCFL tubes. The variations in the build-up curves come from the combinations of (a) the kinds of the phosphor powder, (b) thickness of the phosphor screen, (c) addition of the solid binders to the phosphor powders, and (d) residual gases, A systematic study remains for the future study.

We have already calculated the effort of the eradication of the gap of the lighted FL tubes. The illuminance $\left(\mathrm{lm} \mathrm{m}^{-2}\right)$ of the commercial $40 \mathrm{~W}-\mathrm{HCFL}$ tube will increase to 2.5 times of the present level by the reduction of the depth of the gap. However, the capacitance of the $\mathrm{C}_{\text {tube }}$ in the external $\mathrm{AC}$ driving circuit also increases to about $30 \%$ by the involvement of the $\mathrm{Ar}^{1+}$ in the lighted FL tube. The external $\mathrm{DC}$ electric circuit does not have the induced AC current from the $\mathrm{C}_{\text {tube }}$. However, the HCFL tubes cannot operate with the external DC circuit with the short operation life. You may use the coil-EEFL tubes [2]. The eradication of the gap of the FL tubes is an exciting subject for the improvement of the FL tubes. Figure 6 shows an evidence of the build-up curve of the illuminance that is the commercial CCFL tube with the depth of the gap of $3 \times 10^{-4} \mathrm{~m}$. The temperature of the positive column of the CCFL tube was above $70^{\circ} \mathrm{C}$ with the high $\mathrm{Ar}$ gas pressures above $7 \times 10^{3} \mathrm{~Pa}$ (=50 Torr). The result in Figure 6 indicates that the optimal operation temperature of the FL tubes is not the reported temperature at $40^{\circ} \mathrm{C}[5,6]$. We must solve the puzzle of the optimal operation temperature at $40^{\circ} \mathrm{C}$.

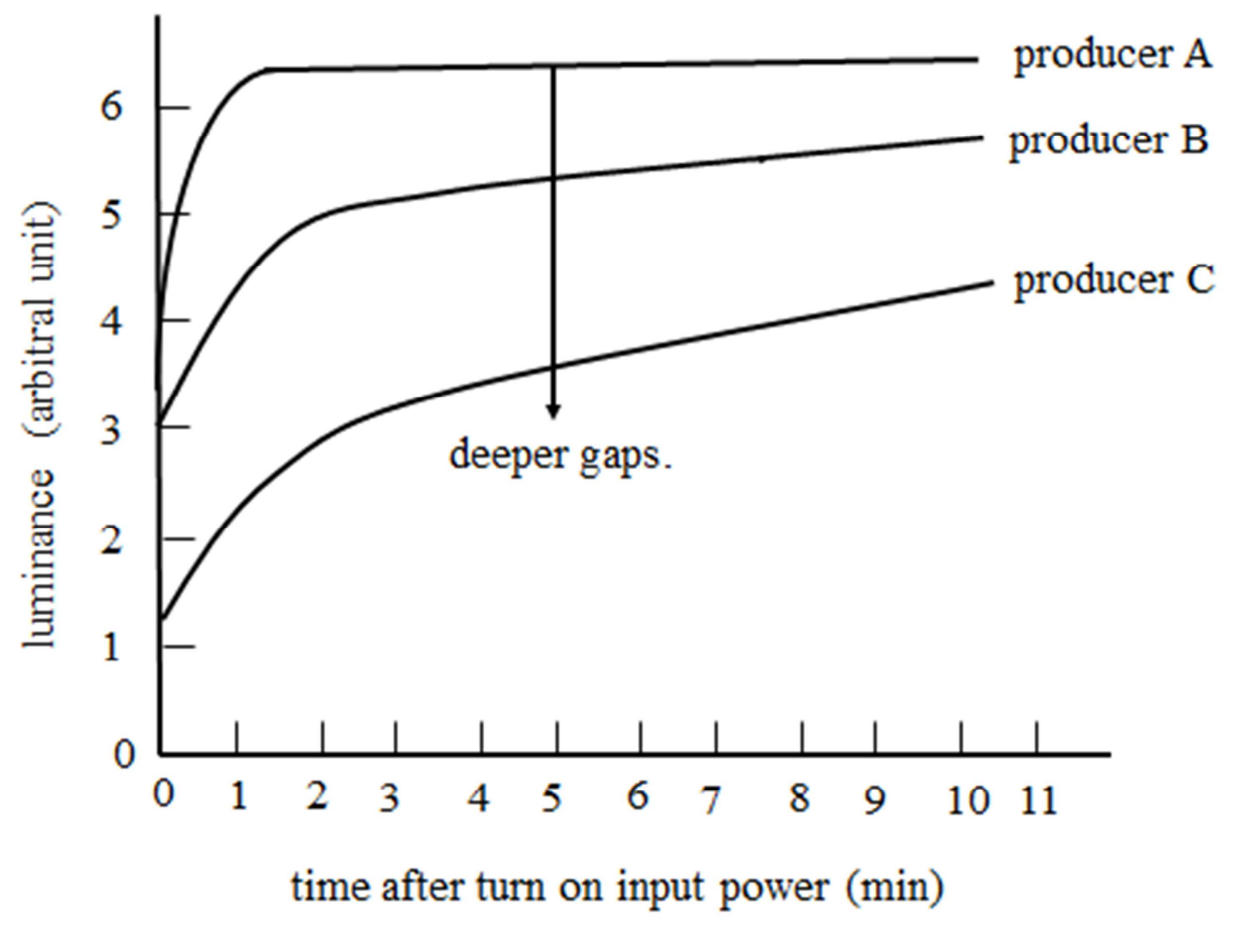

Figure 5. Build-up curve of luminance of commercial 40W-HCFL tube that are produced by the different producers on the market. 


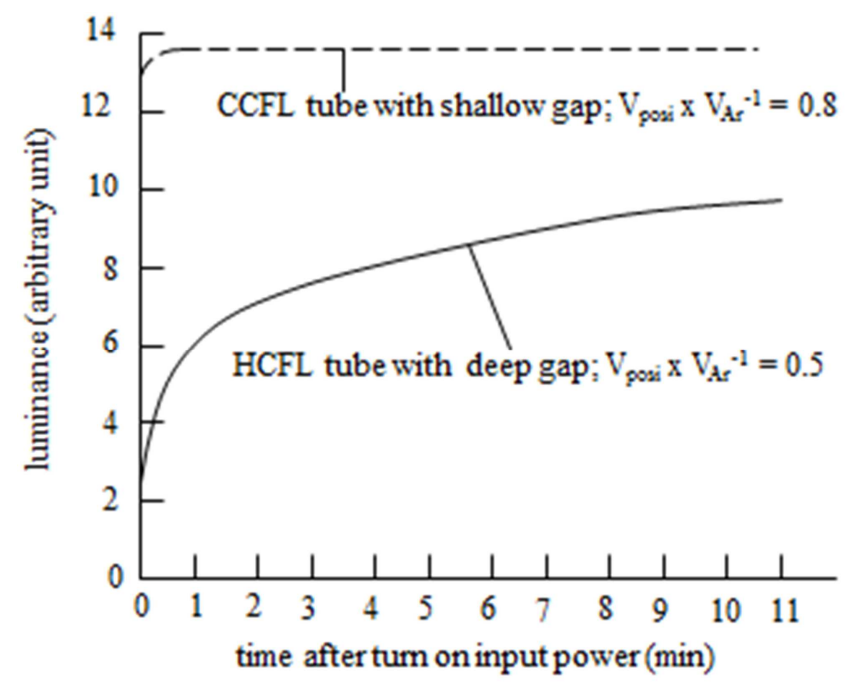

Figure 6. Build-up curves of luminance of commercial CCFL tubes with $3 \times 10^{-4} \mathrm{~m}$ gap and $40 \mathrm{~W}$-HCFL tube with $4 \times 10^{-3} \mathrm{~m}$ gap.

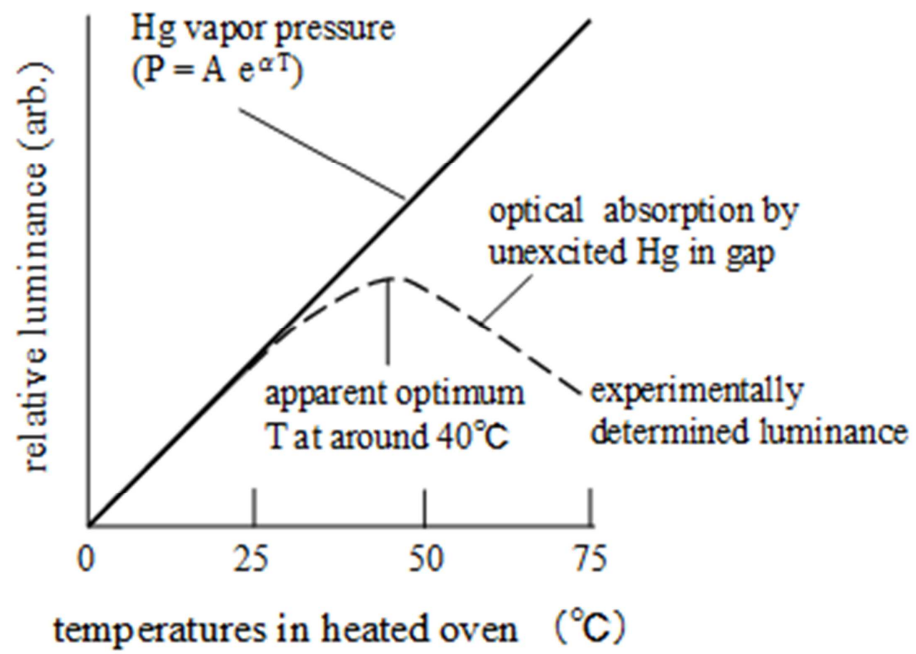

Figure 7. Typical temperature dependence curve of luminance of the FL tubes that sets in heated oven.

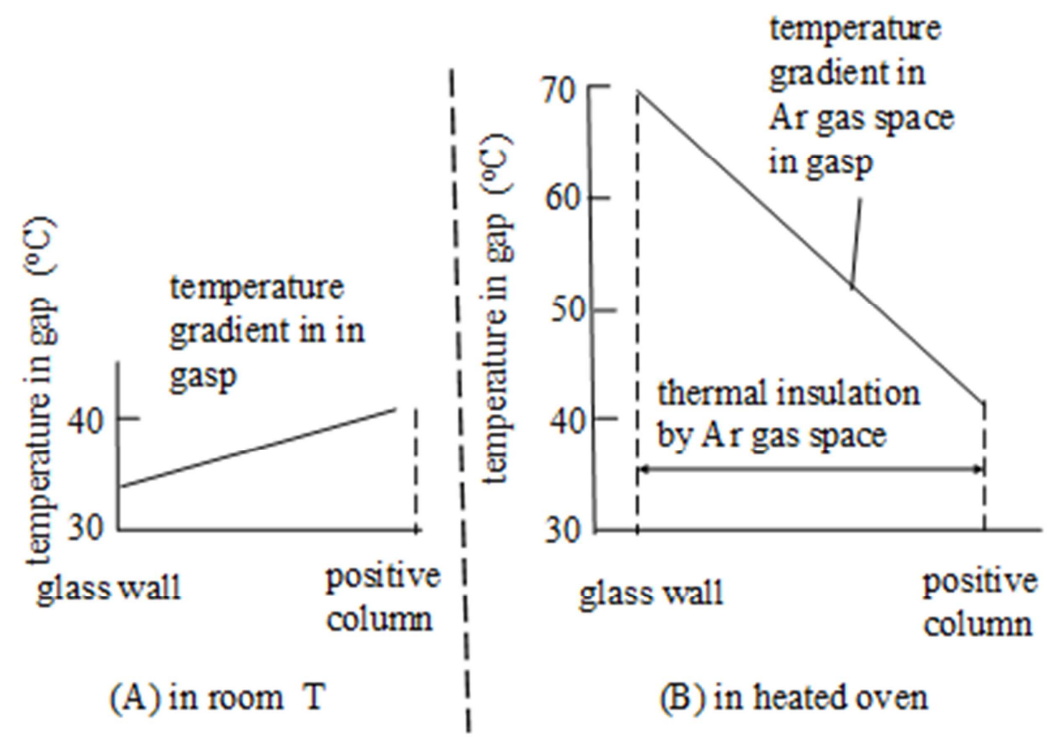

Figure 8. Temperature gradient between positive column and outer glass wall of lighted FL tube. (A) FL tube lights up in room and (B) FL tube lights up in heated oven higher than room temperatures. 


\subsection{Optimal Operation Temperature of FL Tubes}

Figure 7 shows the temperature dependence curve of the typical commercial HCFL tube [5, 6]. The FL tube producers have obstinately believed the optimal operation temperature at around $40^{\circ} \mathrm{C}$ for the FL tubes. There is an experimental difficulty in the determination of the optimal operation temperatures. The FL tubes do not have the control of the heater circuit for the change in the temperatures of the positive column. How do change the operation temperature of the lighted FL tubes? The positive column is surrounded by the good thermal insulator of the gap. We cannot directly heat up the positive column from the heating devices to the various temperatures in the positive column of the lighted FL tube.

I supposed that the experiment of Figure 7 were made by the lighted FL tubes in the heated oven. In this case, the temperature of the Ar gas space at near the glass wall is equal with the temperature of the heated oven. But the temperature of the positive column in the lighted FL tube holds the constant temperature that is generated by the ionization of $\mathrm{Ar}$ atoms in the positive column. The Ar gas space at nearby the glass wall heats to the high temperatures that are equal with the oven temperatures. The Ar gas space at the high temperature contains the high concentrations of the unexcited $\mathrm{Hg}$ atoms. The unexcited $\mathrm{Hg}$ atoms optically absorb the UV lights from the positive column before reaching to the phosphor screen. The temperatures in Figure 7 are not the temperature of the positive column in the lighted FL tube. It is impossible to heat the positive column from the heated oven.

Figure 8 (A) illustrates the temperature gradient between glass wall $\left(30^{\circ} \mathrm{C}\right)$ and positive column $\left(40^{\circ} \mathrm{C}\right)$. Figure 8 (B) illustrates the temperature gradient between positive column $\left(40^{\circ} \mathrm{C}\right)$ and the glass wall of the FL tube in the heated oven $\left(70^{\circ} \mathrm{C}\right)$. Furthermore, the examined HCFL tubes for the measurements had the gaps deeper than $4 \times 10^{-3} \mathrm{~m}$ with the $\mathrm{Ca}_{3}\left(\mathrm{PO}_{4}\right)_{4}(\mathrm{~F}, \mathrm{Cl}): \mathrm{Sb}: \mathrm{Mn}$ phosphor screen. The Ar gas in the deep gap is the good thermal insulator. The positive column has the own heat source that is the ionization of the Ar atoms. We may determine the temperature of the positive column by the infrared thermometer. The temperature of the positive column of the commercial $40 \mathrm{~W}-\mathrm{HCFL}$ tubes is between $35^{\circ} \mathrm{C}$ and $40^{\circ} \mathrm{C}$, depending on the quality of the phosphor screens and the Ar gas pressures. Some FL producers produce their FL tubes with the low Ar gas pressure, e.g., $133 \mathrm{~Pa}$ (=1 Torr), for the reduction of the $\mathrm{W}$ in the luminous efficiency. The FL tubes with the low Ar gas pressure have a short operation life less than 500 hours.

The practical FL tubes should have the high Ar gas pressures as possible. The illuminance $\left(1 \mathrm{~m} \mathrm{~m}^{-2}\right)$ of the FL tubes increases with the high Ar gas pressures, accordingly high temperature of the positive column. The problems with the high $\mathrm{Ar}$ gas pressures are the large active $\mathrm{AC}$ power consumption that is caused by the large capacitance of the $\mathrm{C}_{\text {tube. }}$ If the FL tubes are operated with the external DC power circuit, the electrodes do not pick up the induced $\mathrm{AC}$ current from the $\mathrm{C}_{\text {tube }}$ [2]. The established operation temperature at $40^{\circ} \mathrm{C}$ can be changed with the change in the operation modes of the FL tubes.

\section{Concluding Remarks}

It has pointed out that the technologies of the current FL tubes are not the mature technology. The large room remains for the future study. The Ar gas space of the lighted FL tubes should be studied with the vacuum science, rather than solid-state physics. The Ar atoms float in the vacuum with the separation distance in $2 \times 10^{-7} \mathrm{~m}$. The vacuum in the Ar gas space provides the superconductive vacuum for the moving electrons. The moving electrons in the Ar gas space do not have the electric resistance that gives the Joule Heat. The lights of the FL tubes originate from the excited $\mathrm{Hg}$ atoms that evaporate in the heated Ar gas space of the positive column. The positive column is surrounded by the good thermal insulator of the Ar gas in the gap between positive column and phosphor screen. The depths of the gap determine the performance of the lighted FL tubes. It has demonstrated that the build-up curves of the illuminance $(\mathrm{lm})$ on the control panel of the Ulbricht Sphere provide the new tool for the study on the FL tubes. We may quantitatively analyze the build-up curves.

We have demonstrated that the depths of the gap control the lights from the phosphor screen. The volume of the positive column, $\mathrm{V}_{\text {posi }}$, of the current $40 \mathrm{~W}-\mathrm{HCFL}$ tubes is only $56 \%$ of the total volume of the Ar gases. The residual $43 \%$ volume of the gap contains the unexcited $\mathrm{Hg}$ atoms that act as the optical filter for the UV lights from the positive column. The illuminance $\left(\mathrm{lm} \mathrm{m}^{-2}\right)$ of the commercial 40W-HCFL tubes will have the double illuminance of the present illuminance if the depth of the gap is shallower than $3 \times 10^{-4} \mathrm{~m}$. The previous work [2] had revealed that the AC power consumption of the lighted FL tubes will be nearly zero by the application of the external DC electric circuit to the coil-EEFL tubes. One may allow us to say that the technology of the current FL tubes are the premature technology, remaining the large room for the improvement of the FL tubes, This report theoretically and quantitatively points out the direction of the new technology areas of the FL tubes with the use of the Ulbricht Sphere. The final goal of the FL tubes is the development of the unrivaled FL tubes as illumination source over the power hungry solid-lighting sources, like as the LED lamps that have the energy conversion efficiency between $20 \%$ to $30 \%$.

\section{Acknowledgements}

The author wishes to express his thanks to Dr. Takao Toriu for his guidance of this project.

\section{References}

[1] L. Ozawa and Y. Tian, J. Inf. Display, 11, 128-133, 2010

[2] L. Ozawa, J. China Ill. Engs, Soc., 9. 86-93, 2014 
[3] L. Ozawa and Y. Tian, J. China Ill. Eng, 6, 19-30, 2011

[4] L. Ozawa and Y. Tian, J. China Ill. Eng, 7, 58-65, 2012

[5] Handbook of gas discharge, Japan Institute of Electric Engineers, 1973

[6] J. F. Waymouth, "Electric discharge Lamps", MIT Press, 1971

[7] Fred Rosebury, "Handbook of electron tube and vacuum techniques" American Institute of Physics", New York, 1993
[8] L. Ozawa, "Cathodoluminescence", VCH and Kodansha, Tokyo, Japan, 1990

[9] F. A. Kroger, "Some aspects of the Luminescence of Solids" Elsevier Publishing, New York, 1948

[10] H. W. Leverentz, "An introduction to Luminescence of solids", Jon Willy \& Sons, New York, 1950

[11] Handbook of Physics and Chemistry, CRC Press, Taylor \& Francis, Boca Raton, London, New York 2006 